\title{
Risk factors for antimicrobial resistance in fecal Escherichia coli from preweaned dairy calves
}

\author{
Anna Duse, ${ }^{*}{ }^{1}$ Karin Persson Waller, ${ }^{*} \dagger$ Ulf Emanuelson, $\dagger$ Helle Ericsson Unnerstad, ${ }^{*}$ Ylva Persson, ${ }^{*} \ddagger$ \\ and Björn Bengtsson* \\ *Department of Animal Health and Antimicrobial Strategies, National Veterinary Institute, SE-751 89 Uppsala, Sweden \\ †Department of Clinical Sciences, Swedish University of Agricultural Sciences, SE-750 07 Uppsala, Sweden \\ ¥Växa Sverige, SE-751 05 Uppsala, Sweden
}

\section{ABSTRACT}

The primary objective of this study was to investigate calf and farm factors associated with antimicrobial-resistant Escherichia coli in the feces of preweaned dairy calves in Sweden. In particular, we investigated the effects of feeding calves colostrum and milk from cows treated with antimicrobials. The secondary objective was to describe the prevalence of resistant $E$. coli in feces of preweaned dairy calves in Sweden. Fecal samples from 3 calves, aged 7 to $28 \mathrm{~d}$, from 243 farms were analyzed for the within-sample prevalence of $E$. coli resistant to nalidixic acid, streptomycin, and cefotaxime using selective agars supplemented with antimicrobials. In addition, resistance to 12 antimicrobials was tested in one randomly selected $E$. coli isolate per calf. Information was collected from the farmers via questionnaires regarding the use of colostrum and milk from cows treated with antimicrobials as calf feed and other uses of antimicrobials in the herd. Multivariable zero-inflated negative binomial and logistic regression models were used to assess the effect of various risk factors for shedding of resistant E. coli. Escherichia coli resistant to streptomycin, nalidixic acid, or cefotaxime were isolated from 90,49 , and $11 \%$ of the calves, respectively. Resistance to at least one antimicrobial was found in a random isolate of $E$. coli from $48 \%$ of the calves. Feeding colostrum from cows treated with antimicrobials at drying off did not affect the prevalence of resistant $E$. coli. In contrast, feeding milk from cows treated with antimicrobials during lactation resulted in significantly more nalidixic acid- and streptomycinresistant $E$. coli than when such milk was discarded; no significant effect was seen for other resistance traits. Furthermore, an interaction was found between feeding milk from cows treated with antimicrobials and use of fluoroquinolones in cows. In general, the prevalence of resistance was lower for older calves and calves on

Received June 2, 2014.

Accepted September 23, 2014.

${ }^{1}$ Corresponding author: anna.duse@sva.se small farms. Other factors that were associated with the shedding of resistant $E$. coli were administration of oral dihydrostreptomycin to calves, administration of systemic tetracycline and ceftiofur to cows and calves, housing of the calves, predominant breed of the herd, and geographic location of the farm. The presence of resistant $E$. coli in calves was clearly due to multiple factors, but minimizing the feeding of milk from cows treated with antimicrobials during lactation should lower the prevalence of resistant E. coli in the gastrointestinal tract of the calves.

Key words: waste milk, antibiotic resistance, dairy calf, risk factor

\section{INTRODUCTION}

Infections caused by antimicrobial-resistant bacteria represent an increasing threat to human and animal health (Wernli et al., 2011). Resistance is seen not only in pathogenic bacteria but also in commensal bacteria (Summers, 2002), such as Escherichia coli, which are ubiquitous in the feces of animals and humans (Sørum and Sunde, 2001). Although commensal E. coli strains seldom cause infections, they can harbor resistance genes that may be transferred to pathogenic or opportunistic bacteria, leading to intractable infections (Sørum and Sunde, 2001; Summers, 2002). Commensal $E$. coli from cattle feces are often less resistant to antimicrobials than E. coli from feces of other food animals (European Food Safety Authority, 2011). Young calves are an exception; they often harbor $E$. coli resistant to multiple antimicrobials (DeFrancesco et al., 2004; Sato et al., 2005; SVARM, 2006). Resistant isolates of E. coli from calves may therefore be a significant source of resistance genes for other bacteria in the vicinity (Donaldson et al., 2006; Di Labio et al., 2007).

Antimicrobial resistance is often a consequence of antimicrobial use (van den Bogaard and Stobberingh, 2000). Frequent use of antimicrobials for individual calves has been associated with increased shedding of resistant E. coli (Berge et al., 2005, 2006; Di Labio et al., 2007); however, the effect of antimicrobial therapy 
on resistance in $E$. coli in the gastrointestinal tract of calves seems to be transient (Berge et al., 2006). Overall, the prevalence of resistant $E$. coli in the feces of young calves is high even when the calves have not previously been treated with antimicrobials (Khachatryan et al., 2004; de Verdier et al., 2012). It is therefore likely that there are factors of importance other than antimicrobial treatment.

In several studies, the occurrence of resistant $E$. coli in calf feces has been linked to the age of the calf and it seems to be most abundant during milk feeding (Khachatryan et al., 2004; Watson et al., 2012). Resistance peaks between 2 and 4 wk of age, followed by a gradual decline (Khachatryan et al., 2004; Berge et al., 2005; Watson et al., 2012). During the period when the prevalence of resistance peaks, it is likely that calves are exposed to antimicrobials via ingestion of milk or colostrum from cows treated with antimicrobials. Feeding milk from treated cows is a common practice on many dairy farms (Brunton et al., 2012; Duse et al., 2013). Such milk may contain residues of antimicrobials (Pereira et al., 2014; Randall et al., 2014), which may impose selection pressure on the calves' gastrointestinal bacteria and favor resistant strains. This practice may explain the high prevalence of resistant $E$. coli in preweaned calves (Brunton et al., 2012; Aust et al., 2013; Duse et al., 2013). A few studies have investigated the effect of this feeding practice. Wray et al. (1990) found a significantly higher MIC of streptomycin, but not of ampicillin, in E. coli from calves fed antimicrobialcontaining milk than those fed milk replacer. In another study, a higher prevalence of resistant E. coli, but not of resistant enterococci, was found in calves fed nonpasteurized waste milk compared with bulk tank milk (Aust et al., 2013). Xu et al. (2013) found significantly more $E$. coli producing extended spectrum $\beta$-lactamases (ESBL) among calves from farms that fed milk containing antimicrobial residues than from farms that discarded such milk. Brunton et al. (2014) observed a tendency toward more calves that shed ESBL-producing E. coli and in higher absolute number among calves fed waste milk with antimicrobial residues than calves fed milk replacer. The results of these studies indicate that feeding milk from cows treated with antimicrobials may have some effect on the shedding of resistant E. coli from calves. On the other hand, to our knowledge, the shedding of resistant E. coli from calves fed colostrum or transition milk from cows treated with antimicrobials at drying off has not been studied.

Some of the previous studies in this field failed to take other potential risk factors into account (Wray et al., 1990; Aust et al., 2012; Brunton et al., 2014), although the experiments were conducted under commercial practice, where many factors might influence the shedding of resistant E. coli by calves (Call et al., 2008). In addition, conclusions are often drawn after monitoring the susceptibility of only a single or a few colonies from each calf (Wray et al., 1990; Aust et al., 2013; Xu et al., 2013). The accuracy of this approach is greatly affected by the within-sample prevalence of resistant bacteria (Scott et al., 2011) and by variations in antimicrobial susceptibility among isolates of the same sample (Villarroel et al., 2006).

The primary objective of our study was to investigate the effect of feeding colostrum or milk from cows treated with antimicrobials on the shedding of resistant E. coli in feces from preweaned calves between 7 and 28 d. This relationship was assessed taking the use of antimicrobials and other potential risk factors into account. The secondary objective was to describe the prevalence of antimicrobial resistance among $E$. coli from preweaned dairy calves in Sweden.

\section{MATERIALS AND METHODS}

\section{Selection of Herds}

The number of farms included in the study was based on the assumption that $25 \%$ of Swedish dairy farms feed colostrum from cows treated with antimicrobials at drying off to calves and that this would increase the prevalence of streptomycin resistance in fecal $E$. coli from calves from 30 to $50 \%$. To demonstrate this difference with $95 \%$ confidence and $80 \%$ power, 270 farms had to be included in the study.

The farms were recruited via a questionnaire survey conducted among 457 Swedish dairy farmers in May 2011. The survey inquired about farming practices related to feeding of colostrum and milk from cows treated with antimicrobials (Duse et al., 2013). As the final question in the survey, respondents were given the opportunity to participate in the current study by submitting calf fecal samples for susceptibility testing. Farmers wanting more information before deciding to participate were contacted via telephone in random order before possible inclusion. Of those who agreed to participate, only farms with at least 30 cows were enrolled to simulate a future scenario with larger farms. In total, 287 Swedish dairy farmers were recruited. The median herd size in the study was 75 cows, compared with 66 for all Swedish dairy farms in 2013 with more than 30 cows. (A. Grönvall, Swedish Board of Agriculture, Jönköping, Sweden, personal communication). The farms in the study were located in East (20\%), South (54\%), and North (26\%) Sweden; these divisions are in accordance with the highest subdivision (lands/ NUTS1) using the Nomenclature of Territorial Units for Statistics (European Union, 2003). The figures for 
all Swedish dairy farms ( $\geq 30$ cows) in 2013 were 18, 64, and $23 \%$ for East, South, and North Sweden, respectively (A. Grönvall, Swedish Board of Agriculture, Jönköping, Sweden, personal communication). Thus, in terms of herd size and geographic location, the farms in the study were considered representative of Swedish dairy farms with at least 30 cows.

\section{Sampling}

Each farm was randomly assigned a starting date for sampling between October 2011 and September 2012 , but samples could be submitted until the end of the study in October 2012. Sampling materials, instructions, and submission forms were provided by the National Veterinary Institute (SVA) in Uppsala, Sweden. On each farm, 3 calves were sampled once by the farmer or farm employees. Sampled calves were between 7 and $28 \mathrm{~d}$, visually healthy, and never treated with antimicrobials. Fecal samples were collected from the rectum with Amie's charcoal culture swabs (Copan Diagnostics Inc., Murrieta, CA) and mailed to SVA. Farmers were encouraged to send samples on Sunday through Thursday to ensure that the samples would reach the laboratory before the weekend. Farmers were also requested to fill out a purpose-specific submission form containing the sampling date and age, sex, and type of housing for each sampled calf. The experimental design and all handling of animals were approved by the Uppsala Ethical Committee, Sweden (reference number C88/11).

\section{Sample Analyses}

Fecal samples were analyzed within $48 \mathrm{~h}$ after collection. In short, the percentage of E. coli resistant to streptomycin $\left(\mathbf{S m}^{\mathbf{r}}\right)$, nalidixic acid $\left(\mathbf{N a l}^{\mathrm{r}}\right)$, and cefotaxime $\left(\mathbf{C t x}^{\mathrm{r}}\right)$ with respect to total $E$. coli was determined for each sample. Cefotaxime-resistant isolates of $E$. coli were also investigated for genes encoding ESBL or plasmid-mediated AmpC $\beta$-lactamases $(p A m p C)$. In addition, susceptibility to 12 antimicrobials was determined for one randomly selected isolate of $E$. coli from each sample (details below).

Sample Preparation. Upon arrival, each rectal swab was mixed by vortex in $1 \mathrm{~mL}$ of $0.9 \%$ saline to release fecal content. This fecal suspension constituted the nondiluted suspension $\left(10^{0}\right)$ from which 10-fold dilutions down to $10^{-5}$ were made in $0.9 \%$ saline to enumerate (in cfu) E. coli in the suspensions. The total count of E. coli per sample suspension was estimated by plating $50 \mu \mathrm{L}$ of dilutions $10^{-3}$ and $10^{-5}$ on one-half each of a MacConkey agar plate (Difco, Basingstoke, UK). The count of $\mathrm{Sm}^{\mathrm{r}}$ E. coli was estimated by plating
$50 \mu \mathrm{L}$ of dilutions $10^{-1}$ and $10^{-3}$ on one-half each of a MacConkey agar plate supplemented with $32 \mu \mathrm{g} / \mathrm{mL}$ streptomycin sulfate salt (Sigma-Aldrich Co., St. Louis, MO) each. The count of $\mathrm{Nal}^{\mathrm{r}} E$. coli was estimated by plating $50 \mu \mathrm{L}$ of dilutions $10^{0}$ and $10^{-2}$ on one-half each of a MacConkey agar plate supplemented with $32 \mu \mathrm{g} /$ $\mathrm{mL}$ nalidixic acid sodium salt (Sigma-Aldrich Co.). The count of $\mathrm{Ctx}^{\mathrm{r}}$ E. coli was estimated by plating $100 \mu \mathrm{L}$ of the nondiluted suspension $\left(10^{0}\right)$ on a MacConkey agar plate supplemented with $1 \mu \mathrm{g} / \mathrm{mL}$ cefotaxime sodium salt (Sigma-Aldrich Co.). Dilutions were selected based on a pilot study (A. Duse, unpublished data). The inoculated agar plates were incubated overnight at $37^{\circ} \mathrm{C}$.

Within-Sample Prevalence of Antimicrobial Resistant $\boldsymbol{E}$. coli. Red or pink colonies with a colony morphology resembling $E$. coli were enumerated on plates with and without supplemented antimicrobials. In a pilot study (A. Duse, unpublished data) with these methods, at least $97 \%$ of the colonies meeting the above criteria were confirmed as E. coli by testing for production of tryptophanase (indole) and $\beta$-Dglucopyanosiduronic acid (PGUA). Isolates of E. coli growing on an agar plate supplemented with antimicrobials were regarded as resistant. To determine the proportion of resistant E. coli (\%) in each sample suspension and for each antimicrobial, the number of resistant $E$. coli isolates was divided by the total number of isolates and multiplied by 100. Quality control was conducted for each new batch of agar, using E. coli ATCC 25922 as a susceptible reference strain, and E. coli 4.7 and $E$. coli 1.6, obtained from the European Union Reference Laboratory-Antimicrobial Resistance (EURL-AR, National Food Institute, Lyngby, Denmark), as $\mathrm{Nal}^{\mathrm{r}} / \mathrm{Sm}^{\mathrm{r}}$ and $\mathrm{Ctx}^{\mathrm{r}}$ reference strains, respectively. The quality control results were all within acceptable ranges. The methods described above to measure the within-sample prevalence of resistant $E$. coli were modified from the methods used by Vieira et al. (2008).

Antimicrobial Susceptibility Testing of a Random Isolate of $\boldsymbol{E}$. coli. One lactose-fermenting colony with typical E. coli morphology was randomly selected from the MacConkey agar plate without antimicrobial. This colony was subcultured on horse blood agar (Oxoid, Basingstoke, UK) incubated overnight at $37^{\circ} \mathrm{C}$, and tested for production of tryptophanase (indole), using the spot indole test (Miller and Wright, 1982). Lactose- and indole-positive isolates with typical colony morphology were considered E. coli. These isolates were tested for the susceptibility to 12 antimicrobials by determination of MIC with broth microdilution. Testing was completed according to recommendations by the Clinical and Laboratory Institute (CLSI, 2013) using VetMIC panels (National Veterinary Institute, Uppsala, Sweden) and cation-adjusted Mueller Hinton broth 
Table 1. The proportion of resistance and the $\mathrm{MIC}_{50}$ and $\mathrm{MIC}_{90}$ among isolates of Escherichia coli from feces of preweaned dairy calves in Sweden for 12 antimicrobials $(\mathrm{n}=729)^{1}$

\begin{tabular}{lccccc}
\hline Antimicrobial & $\begin{array}{c}\text { Range tested } \\
(\mathrm{mg} / \mathrm{L})\end{array}$ & $\begin{array}{c}\text { Cut-off value } \\
(\mathrm{mg} / \mathrm{L})\end{array}$ & $\begin{array}{c}\text { Resistance } \\
(\%)\end{array}$ & $\begin{array}{c}95 \% \\
\mathrm{CI}\end{array}$ & $\begin{array}{c}\mathrm{MIC}_{50} \\
(\mu \mathrm{g} / \mathrm{mL})\end{array}$ \\
\hline Ampicillin & $1-128$ & $>8$ & 19.3 & $16.4 ; 22.2$ & 2 \\
$(\mu \mathrm{g} / \mathrm{mL})$
\end{tabular}

${ }^{1}$ Cut-off value according to the epidemiological cut-off values established by EUCAST; $\mathrm{MIC}_{50}$ and $\mathrm{MIC}_{90}=$ MIC that inhibit 50 and $90 \%$ of the isolates, respectively.

(Becton Dickinson, Cockeysville, MD). Antimicrobials and ranges are given in Table 1. Quality control, using the reference strain E. coli ATCC 25922, was conducted in parallel with each batch of isolates; all results were within acceptable ranges. Epidemiological cut-off values (Table 1) issued by the European Committee on Antimicrobial Susceptibility Testing (EUCAST; www. eucast.org) were used to classify isolates as susceptible or resistant.

Detection of Genes Encoding for ESBL or $\boldsymbol{p A m p C} \boldsymbol{\beta}$-Lactamases. One lactose-fermenting colony with $E$. coli morphology was randomly selected from the cefotaxime-supplemented MacConkey agar plate. This colony was subcultured on horse blood agar (Oxoid) and incubated overnight at $37^{\circ} \mathrm{C}$. Isolates were considered as $E$. coli if positive in the spot indole test (Miller and Wright, 1982). Confirmed isolates were screened by multiplex-PCR for detection of the following gene groups: plasmid-mediated AmpC $(p A m p C$; Pérez-Pérez and Hanson, 2002) and $b l a_{\mathrm{CTX-M}}$ (Woodford et al., 2006). Specific gene variants were determined by sequencing using BigDye v1.1 (Life Technologies, Grand Island, NY) and the following primers: $b l a_{\mathrm{CTX}}$ M-1, 5'-CAGAATAAGGAATCCCATGGTT-3' and 5'-GGCGATAAACAAAAACGGAAT-3'; and bla $a_{\mathrm{CMY}-2}$, 5'-AAATCGTTATGCT(G/C)CGCTCT-3' and 5'-CATGGGATTTTCCTTGCTGT-3' (Sundsfjord et al., 2004).

\section{Collection and Management of Risk Factor Data}

Risk factor data for the 243 farms were collected via 3 channels: national database records, a questionnaire survey conducted before the study (questionnaire 1), and a second one conducted in relation to the sampling (questionnaire 2).
Data Obtained via National Databases. Information regarding geographic location and the predominant herd breed (Table 2) was obtained from the Swedish Official Milk Recording Scheme (SOMRS). The farms geographic location was defined by the highest subdivision (lands/NUTS1) using the Nomenclature of Territorial Units for Statistics (East Sweden, South Sweden including the islands, and North Sweden; European Union, 2003). The predominant breed of the cows on the farm was defined as Swedish Holstein or Swedish Red when more than $75 \%$ of the cows were of these breeds. When none of these breeds exceeded $75 \%$ of the cows in the herd, the breed was classified as mixed. Additionally, recorded data on veterinary use of antimicrobials during the 2 preceding years were collected from the dairy disease database (DDD) administered by Växa Sverige (Mörk et al., 2010).

Questionnaire 1. A web-based questionnaire survey was conducted in 2011 to obtain information describing farming practices related to feeding milk and colostrum from cows treated with antimicrobials to calves (Duse et al., 2013). The questionnaire is described in detail in Duse et al. (2013). Colostrum and transition milk (i.e., milk from the second milking to the fourth day after calving) from a cow that was treated with antimicrobials at dry off were designated waste colostrum (WC) and waste transition milk (WT), respectively. Milk produced by a cow that was treated with antimicrobials during lactation was denoted as waste milk (WM). The farms were categorized as "always to occasionally" or "never" feeding WC to calves (Table 2). The farms were likewise categorized with respect to WT (Table 2). Finally, farms were categorized with respect to the feeding of WM to calves: "always to occasionally" (during the treatment period, the statutory withdrawal period, or both) or "never" (Table 2). Besides categorization of 
Table 2. Farm- and calf-level variables in the univariable analysis for antimicrobial-resistant Escherichia coli in feces from preweaned dairy calves ( $\mathrm{n}=243$ farms, 729 calves)

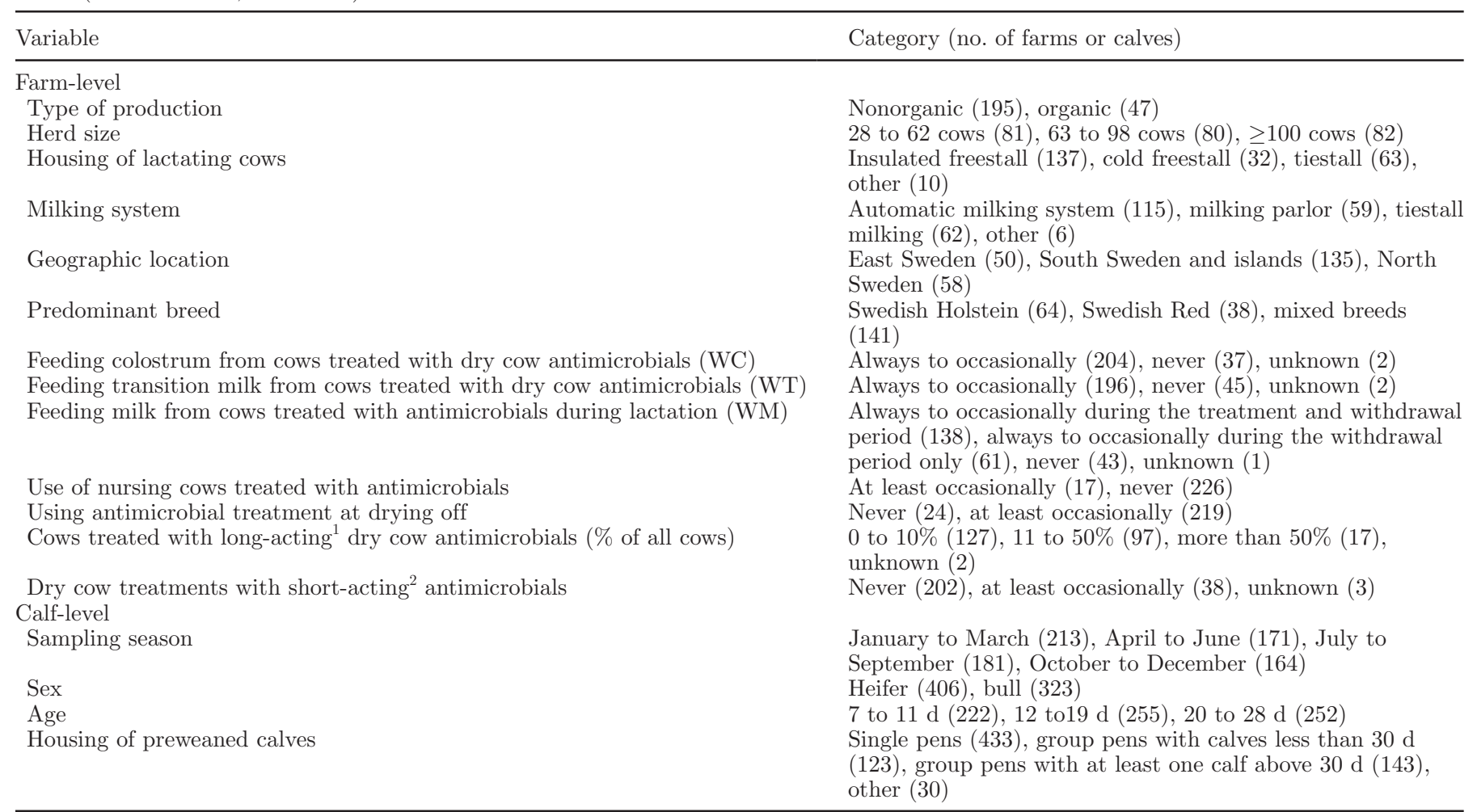

\footnotetext{
${ }^{1}$ Long-acting dry cow antimicrobials provide sustained concentrations when administered intramammary and must be administered at least 4 wk before calving to deliver milk for human consumption $4 \mathrm{~d}$ after calving. In this study, long-acting dry cow antimicrobials were benzylpenicillin with either framycetin or dihydrostreptomycin.

${ }^{2}$ Short-acting antimicrobials for dry cow therapy do not provide sustained concentrations and therefore, repeated administration is necessary. These formulas can be used in lieu of long-acting formulas to avoid subtherapeutic concentrations over several days and to minimize the risk of residues in milk. In this study, short-acting dry cow antimicrobials were either benzylpenicillin alone or in combination with dihydrostreptomycin.
}

farms based on the feeding of WC, WT, and WM, the questionnaire surveyed the production type (organic vs. nonorganic) of the farm (Table 2).

Questionnaire 2. The purpose of the second survey was to obtain information on the types of antimicrobials used on the farms, and treatment incidence (TI) of cows and preweaned calves. As in the first questionnaire, the second one was conducted using the online survey platform Easyresearch (Questback; http://www. questback.com) via an e-mail link. The questionnaire used conditional branching to follow-up questions based on the answers to the previous question; only closedended questions were used. Questions about antimicrobials included the names of the active substance, names of the available preparations, and pictures thereof. The respondents were asked to provide a crude measure of the frequency of treatments for the most commonly used antimicrobials in Sweden (Växa Sverige, 2012). The scale, in descending order of frequency, was "several times a week," "several times a month," "several times a year," "few times a year," and "never."
Antimicrobial consumption was described both as a binary variable (using/not using) and mean annual TI (Table 3). To estimate the TI, the response options from questionnaire 2 were transformed to an estimated number of treatments per year as follows. "Several times a week" was set to approximately correspond to 104 cases $(2 \times 52 \mathrm{wk})$, "several times a month" to 48 cases $(4 \times 12 \mathrm{mo})$, "several times a year" to 12 cases, "few times a year" as 4 cases, and "never." This number was then related to the herd size and multiplied by 100 to obtain an estimated treatment incidence $\left(\mathbf{T I}_{\mathbf{e}}\right)$, expressed as cases per 100 cow-years.

Likewise, the mean number of recorded cases of antimicrobial treatments from the DDD during a year was related to the herd size of the farm and multiplied by 100 to obtain the recorded treatment incidence $\left(\mathbf{T I}_{\mathbf{r}}\right)$, expressed as cases per 100 cow-years. The coverage of the DDD in Sweden is less than 100\% due to underreporting (Mörk et al., 2010). To avoid underestimation, the highest value of either the $\mathrm{TI}_{\mathrm{e}}$ or the $\mathrm{TI}_{\mathrm{r}}$ for each farm was therefore used as the TI for further analyses. 
Table 3. Mean, 95\% CI, minimum, median, and maximum of the annual treatment incidence (TI) for the most commonly used antimicrobials for cows and preweaned dairy calves in 243 Swedish dairy farms

\begin{tabular}{|c|c|c|c|c|c|c|c|}
\hline $\begin{array}{l}\text { Antimicrobial } \\
\text { ( } \% \text { of farms where data were available) }\end{array}$ & Route & $\begin{array}{l}\text { No. of farms } \\
(\%)^{1}\end{array}$ & Mean & $95 \% \mathrm{CI}$ & Minimum & Median & Maximum \\
\hline Benzylpenicillin (99.6\%) & Systemic & $239(98.8)$ & 27.7 & $26.2 ; 29.2$ & 0 & 22.5 & 111.6 \\
\hline $\begin{array}{l}\text { Benzylpenicillin or benzylpenicillin/DHS } \\
\text { combination }(99.2 \%)\end{array}$ & $\mathrm{IMM}^{3}$ & $137(56.4)$ & 6.3 & $5.6 ; 7.0$ & 0 & 2.8 & 78.7 \\
\hline Ceftiofur $(98.4 \%)$ & Systemic & $47(19.7)$ & 1.4 & $1.2 ; 1.9$ & 0 & 0 & 20.0 \\
\hline Tetracycline $(98.8 \%)$ & Intrauterine & $77(32)$ & 2.2 & $1.1 ; 3.3$ & 0 & 0 & 37.5 \\
\hline Tetracycline $(97.9 \%)$ & Systemic & $144(60.5)$ & 4.5 & $4.2 ; 4.8$ & 0 & 3.3 & 30.7 \\
\hline \multicolumn{8}{|l|}{ Preweaned calves } \\
\hline Benzylpenicillin (99.2\%) & Systemic & $194(80.5)$ & 6.5 & $6.0 ; 7.0$ & 0 & 5.3 & 56.5 \\
\hline Benzylpenicillin/DHS combination (98.7\%) & Systemic & $44(18.3)$ & 1.1 & $0.9 ; 1.3$ & 0 & 0 & 17.1 \\
\hline Ceftiofur $(99.2 \%)$ & Systemic & $2(0.8)$ & 0.1 & $0.05 ; 0.2$ & 0 & 0 & 9.6 \\
\hline $\operatorname{DHS}^{2}(99.1 \%)$ & Oral & $46(19.1)$ & 1.6 & $1.3 ; 1.9$ & 0 & 0 & 21.8 \\
\hline
\end{tabular}

${ }^{1}$ Number and proportion of farms where the antimicrobial is used.

${ }^{2}$ Dihydrostreptomycin.

${ }^{3}$ Intramammary.

As underreporting is even more common for antimicrobial treatments of calves (Mörk et al., 2009), only the $\mathrm{TI}_{\mathrm{e}}$ was used as the TI of antimicrobial treatments of preweaned dairy calves (Table 3 ).

Besides information regarding antimicrobial consumption in cows and preweaned calves, data were also obtained from questionnaire 2 regarding current herd size, predominant housing type for lactating cows and predominant milking system [i.e., automatic milking system (AMS), milking parlor, tiestall milking, or other; Table 2].

Neither of the questionnaires contained questions that could interfere with the personal integrity of the respondents. Hence, in accordance with the act on ethical review of research involving humans (SFS 2003:460) in the Swedish Code of Statutes, an ethical approval for research on humans was not deemed necessary. In accordance with the Helsinki Declaration, several precautions to maintain the personal integrity of the farmers were implemented. These included decoding the farm identification number in the data, keeping personal information confidential, and removing survey data and e-mails from the online platform. The questionnaires in Swedish can be obtained upon request from the corresponding author.

\section{Statistical Analysis}

Data were entered in a Microsoft Excel spreadsheet (Microsoft Corp., Redmond, WA) and exported into Stata 11 (release 11.2; Stata Statistical Software, College Station, TX) for analysis. The association of poten- tial predictor variables to the within-sample prevalence of $\mathrm{Sm}^{\mathrm{r}}$ or $\mathrm{Nal}^{\mathrm{r}}$ E. coli was assessed using zero-inflated negative binomial regression with the ZINB function in Stata. A robust variance estimator was used to account for the clustering of observations at the herd level. Zeroinflated negative binomial regression models are used to handle count data for which the variance is greater than the mean (over-dispersion) and where there is an excess of zero counts (observations with zero resistant E. coli isolates; Dohoo et al., 2010). These types of models include the negative binomial part (which models the within-sample prevalence of resistant $E$. coli isolates in the sample) and the logistic regression part (which models the probability of isolating zero resistant E. coli isolates in the sample; Dohoo et al., 2010).

Potential predictor variables (Tables 2 and 3 ) were tested both in the logistic and negative binomial parts of the model. Only a small proportion of the calves (77 out of 729) carried $\mathrm{Ctx}^{\mathrm{r}}$ E. coli; therefore, it was not possible to use the within-sample prevalence of $\mathrm{Ctx}^{\mathrm{r}} E$. coli as an outcome variable in the analyses. Instead, this variable was modeled as a binary outcome variable; that is, the calves had either at least one $\mathrm{Ctx}^{\mathrm{r}} E$. coli isolate or none. The association of potential predictor variables (Tables 2 and 3) with the presence or absence of $\mathrm{Ctx}^{\mathrm{r}}$ E. coli or with antimicrobial resistance of a random isolate of $E$. coli was assessed by univariable logistic regression using the LOGIT function in Stata. A robust variance estimator was used to account for the clustering of observations at the herd level.

Collinearity was assessed pair-wise by calculation of Spearman rank correlations. Variables with a $P$-value 
$<0.2$ were considered for multivariable analysis, provided that there was no collinearity $(\mathrm{r}<|0.7|)$ between them. The assumption of linearity between continuous predictor variables and outcome variables was checked visually with the LINTREND function in Stata. Continuous variables that were not linearly related to the outcomes were categorized using either biologically important cut-off values or cut-off values that resulted in even-sized groups. Antimicrobial use (Table 3) was included as either continuous or categorical variables (using/not using), depending on whether the assumption of linearity was fulfilled. Categories with too few observations $(<5)$ were amalgamated with another category to constitute a biologically plausible one.

For each outcome, a single multivariable model was developed using a manual, backward-stepwise procedure. Potential confounders were considered in every model as variables that if present, changed the coefficient for one or more variable by more than $30 \%$ (Houe et al., 2004). All variables with a $P$-value $\leq 0.05$ were retained in the final model. All biologically plausible interactions between remaining main effects were tested; a $P$-value $\leq 0.05$ was considered evidence of interaction. Model fit was investigated by generating and comparing expected probabilities to observed probabilities. To assess the fit of binary dependent variables, we used the Hosmer-Lemeshow goodness-of-fit test with the data partitioned in up to 10 deciles. Models were developed for resistance in a random isolate of $E$. coli for ampicillin $\left(\mathbf{A} \mathbf{m}^{\mathbf{r}}\right)$, nalidixic acid $\left(\mathrm{Nal}^{\mathrm{r}}\right)$, ciprofloxacin $\left(\mathbf{C i}^{\mathbf{r}}\right)$, streptomycin $\left(\mathrm{Sm}^{\mathrm{r}}\right)$, tetracycline $\left(\mathbf{T c}^{\mathrm{r}}\right)$, sulfametoxazole $\left(\mathbf{S u}^{\mathrm{r}}\right)$, chloramphenicol $\left(\mathbf{C m}^{\mathrm{r}}\right)$, and kanamycin $\left(\mathbf{K m}^{\mathrm{r}}\right)$. A multivariable model could not be developed for trimethoprim due to the lack of significant predictor variables, nor could it be developed for florfenicol or gentamicin due to low prevalence/absence of resistant isolates.

Significant predictors of the final zero-inflated negative binomial regression models were described with coefficients and robust standard errors, separated in the logistic and the negative binomial part of the model (Tables 4 and 5). Significant predictors of the final logistic regression models were described with coefficients, robust standard errors, and odds ratios (Tables 6 to 8 ).

\section{RESULTS}

\section{Samples and Farms}

Sampling material and questionnaires were distributed to 286 of the 287 farms. One farm withdrew before the designated sampling period. In total, 756 fecal samples were received from 248 farms ( $87 \%$ response). Of these samples, 14 were from calves outside the correct age span and 4 were from farms that had already submitted samples from 3 calves. These samples were therefore excluded. Four farms submitted only 2 samples each and 1 farm submitted only 1 sample; these data were also excluded. In total, samples from 729 calves on 243 farms were used. The median age of the calves was 15 d, ranging from 7 to $28 \mathrm{~d}$. The distribution of the calf age, sex, and housing type, as well as the distribution of samples obtained in different seasons are described in Table 2. The median herd size for the 243 farms was 72 cows, ranging from 28 to 1,175 cows. Table 2 shows the distribution of farms within groups by herd size, production type (nonorganic or organic), predominant milking system (AMS, milking parlor, tiestall milking, or other), housing of lactating cows, geographic location, and predominant herd breed.

\section{Antimicrobial Susceptibility}

Within-Sample Prevalence of Antimicrobial Resistant E. coli. Streptomycin-resistant E. coli were isolated from $90 \%$ of the calves, representing $96 \%$ of the 243 farms. Streptomycin-resistant E. coli were isolated from all 3 calves ( $82 \%$ of the farms), 2 calves $(8 \%)$, only 1 calf $(6 \%)$, and no calf $(4 \%)$. The within-sample prevalence of $\mathrm{Sm}^{\mathrm{r}}$ E. coli for individual calves ranged from 0 to $100 \%$, where the median, 25 th, and 75 th percentiles were $4,0.07$, and $32 \%$, respectively.

Nalidixic acid-resistant $E$. coli were isolated from $49 \%$ of the calves, representing $60 \%$ of the 243 farms. Nalidixic acid-resistant E. coli were isolated from no calf (40\% of the farms), all 3 calves (37\%), 2 calves (14\%), and only 1 calf (9\%). The within-sample prevalence of $\mathrm{Nal}^{\mathrm{r}}$ E. coli for individual calves ranged from 0 to $100 \%$ and the median, 25 th, and 75 th percentiles were 0,0 , and $0.5 \%$, respectively.

Cefotaxime-resistant E. coli were isolated from $11 \%$ of the calves, representing $18 \%$ of the 243 farms. Cefotaxime-resistant E. coli were isolated from no calf $(82 \%$ of the farms), only 1 calf (9\%), 2 calves (5\%), and all calves (4\%). The within-sample prevalence of $\mathrm{Ctx}^{\mathrm{r}} E$. coli for individual calves ranged from 0 to $78 \%$, and the median, 25th, and 75 th percentiles were all $0 \%$.

Antimicrobial Susceptibility Testing of a Random Isolate of $\boldsymbol{E}$. coli. Of the 729 randomly selected $E$. coli isolates subjected to antimicrobial susceptibility testing, 352 (48\%) were resistant to one or more antimicrobials. Distribution of MIC and the proportion of resistance to antimicrobials tested are presented in Table 1. Of the isolates, $197(27 \%)$ were resistant to 3 or more antimicrobials (multiresistant) and $61(8 \%)$ to 5 or more. Of the 197 multiresistant isolates, the most common phenotype was resistance to streptomycin, sulfametoxazole, and tetracycline (115 isolates). 
Table 4. Risk factors for an increased prevalence of streptomycin-resistant Escherichia coli in fecal samples from preweaned dairy calves (n $=$ 729 ) according to a multivariable zero-inflated negative binomial regression model

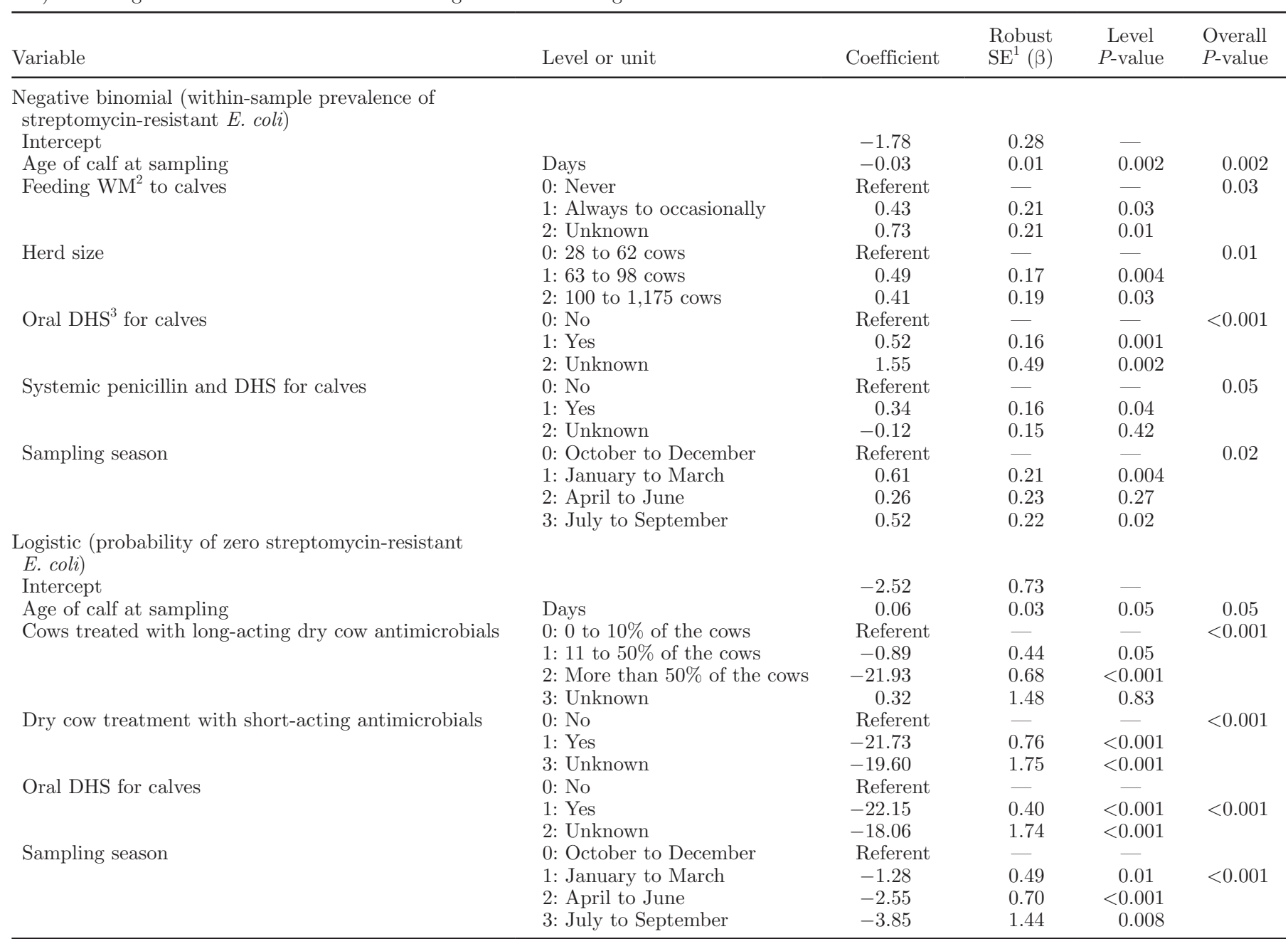

${ }^{1}$ Robust standard errors (adjusted by clustering within herds).

${ }^{2}$ Milk produced by a cow that was treated with antimicrobials during lactation.

${ }^{3}$ Dihydrostreptomycin.

Detection of Genes Encoding ESBL or pAmpC $\boldsymbol{\beta}$-Lactamases. Cefotaxime-resistant E. coli were isolated from 81 calves. Nine of these calves (1\% of all calves) from 5 farms carried $E$. coli with genes encoding either ESBL or transferrable pAmpC. Four of these isolates carried $b l a_{\text {СтX-M-15 }}, 1$ carried $b l a_{\text {CTX-м-1 }}$, and 4 carried bla $a_{\mathrm{CMY}-2}$. The remaining 72 isolates did not carry any of these transferable genes; decreased susceptibility to cefotaxime among these could be the result of mutations causing hyperproduction of AmpC $\beta$-lactamases.

\section{Risk Factors Associated With the Shedding of Antimicrobial-Resistant E. coli}

Feeding Colostrum or Milk From Cows Treated With Antimicrobials to Calves. Feeding of WC
(Figure 1) or WT was not significantly associated with a high within-sample prevalence of $\mathrm{Sm}^{\mathrm{r}}$ or $\mathrm{Nal}^{\mathrm{r}}$ E. coli (Tables 4 and 5). Likewise, the odds of isolating at least one $\operatorname{Ctx}^{\mathrm{r}}$ E. coli (Table 6) or a random E. coli resistant to any of the other tested antimicrobials (Tables 7 and 8) were not significantly higher among calves on farms that fed either WC or WT than on farms that discarded WC or WT.

Calves from farms that fed WM to calves had a higher within-sample prevalence of $\mathrm{Sm}^{\mathrm{r}}$ and $\mathrm{Nal}^{\mathrm{r}} E$. coli than calves on farms where WM was not fed to calves (Figure 2). We detected no significant difference between feeding WM produced during the withdrawal period and feeding WM during both the treatment and the withdrawal period (Figure 2). Therefore, these 2 categories were amalgamated into one in the analyses. 
Table 5. Risk factors for increased prevalence of nalidixic acid-resistant Escherichia coli in fecal samples from preweaned dairy calves $(\mathrm{n}=720)$, according to a multivariable zero-inflated negative binomial regression model

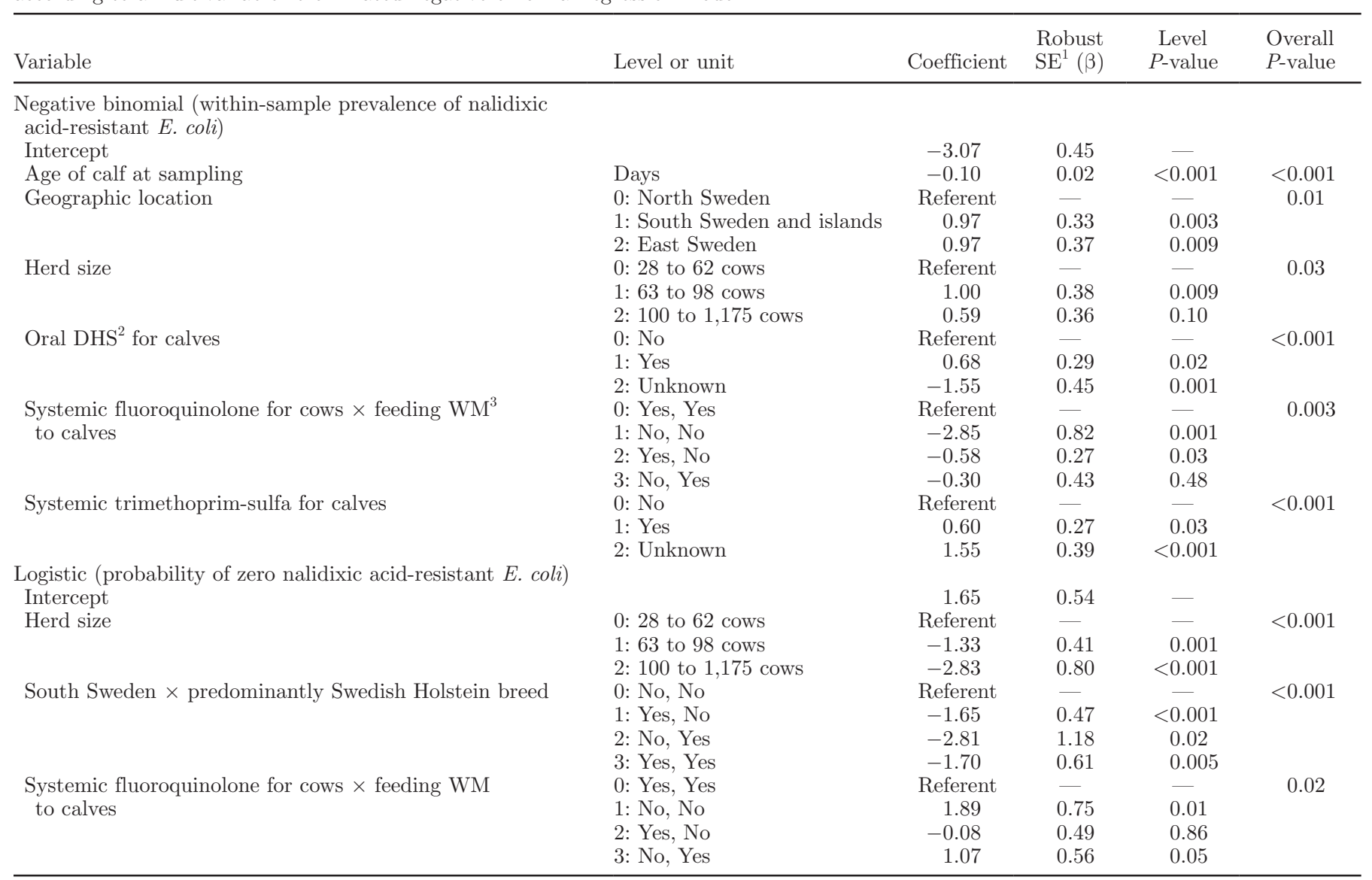

${ }^{1}$ Robust standard errors (adjusted for clustering within herds).

${ }^{2}$ Dihydrostreptomycin.

${ }^{3}$ Milk produced by a cow that was treated with antimicrobials during lactation was here denoted as waste milk.

We detected a significant interaction between using fluoroquinolones in cows and feeding WM to calves. Farms that did both had a significantly higher withinsample prevalence of $\mathrm{Nal}^{\mathrm{r}} E$. coli among their calves than farms that neither fed WM to calves nor treated cows with fluoroquinolones (Table 5).
Feeding WM to calves also resulted in increased likelihood of $\mathrm{Nal}^{\mathrm{r}}$ (Table 8) or $\mathrm{Sm}^{\mathrm{r}}$ (Table 7) in a random isolate of $E$. coli compared with not feeding WM to calves. However, the prevalence of resistance to the remaining tested antimicrobials was not significantly higher for calves on farms feeding WM to calves, al-

Table 6. Risk factors for the presence of at least 1 cefotaxime-resistant isolate of Escherichia coli in feces from preweaned dairy calves $(\mathrm{n}=$ $723)$, according to a multivariable logistic regression model

\begin{tabular}{|c|c|c|c|c|c|c|c|}
\hline Variable & Level or unit & Coefficient & $\begin{array}{l}\text { Robust } \\
\mathrm{SE}^{1}(\beta)\end{array}$ & $\begin{array}{l}\text { Odds } \\
\text { ratio }\end{array}$ & $\begin{array}{c}95 \% \\
\mathrm{CI}\end{array}$ & $\begin{array}{c}\text { Level } \\
P \text {-value }\end{array}$ & $\begin{array}{l}\text { Overall } \\
P \text {-value }\end{array}$ \\
\hline Intercept & & -3.54 & 0.50 & & & & \\
\hline \multirow{2}{*}{ Calf housing } & 1: Group pens & 0.97 & 0.30 & 2.65 & $1.48 ; 4.75$ & 0.001 & \\
\hline & 2: Other & -0.93 & 1.07 & 0.40 & $0.05 ; 3.23$ & 0.39 & \\
\hline \multirow[t]{2}{*}{ Herd size } & $0: 28$ to 62 cows & Referent & - & - & - & - & 0.04 \\
\hline & 1: 63 to 98 cows & 1.21 & 0.53 & 3.36 & $1.19 ; 9.51$ & 0.02 & \\
\hline $\begin{array}{l}\text { Systemic ceftiofur treatments } \\
\text { of calves }\end{array}$ & 1: Yes & 0.90 & 0.21 & 2.46 & $1.62 ; 3.73$ & $<0.001$ & \\
\hline
\end{tabular}

${ }^{1}$ Robust standard errors (adjusted for clustering within herds). 
Table 7. Risk factors for resistance to ampicillin, streptomycin, tetracycline or kanamycin in a random isolate of Escherichia coli in feces from preweaned dairy calves (n $=726-729$ ), according to multivariable logistic regression models

\begin{tabular}{|c|c|c|c|c|c|c|c|c|}
\hline $\begin{array}{l}\text { Resistance } \\
\text { phenotype }\end{array}$ & Variable & Level or unit & Coefficient & $\begin{array}{l}\text { Robust } \\
\text { SE }(\beta)^{1}\end{array}$ & $\begin{array}{l}\text { Odds } \\
\text { ratio }\end{array}$ & $\begin{array}{c}95 \% \\
\text { CI }\end{array}$ & $\begin{array}{c}\text { Level } \\
P \text {-value }\end{array}$ & $\begin{array}{l}\text { Overall } \\
P \text {-value }\end{array}$ \\
\hline \multirow[t]{9}{*}{ Ampicillin } & Intercept & & -0.77 & 0.39 & & & & \\
\hline & Age of calf at sampling & Days & -0.09 & 0.02 & 0.91 & $0.88 ; 0.95$ & $<0.001$ & \\
\hline & \multirow[t]{4}{*}{ Predominant milking system } & 0: Tie stall milking & Referent & - & - & - & - & \multirow[t]{4}{*}{$<0.001$} \\
\hline & & 1: Milking parlor & 1.10 & 0.37 & 3.01 & $1.46 ; 6.21$ & 0.003 & \\
\hline & & 2: Automatic milking system (AMS) & 0.38 & 0.33 & 1.46 & $0.77 ; 2.79$ & 0.25 & \\
\hline & & 3: Other & 1.70 & 0.49 & 5.46 & $2.07 ; 14.39$ & 0.001 & \\
\hline & \multirow[t]{3}{*}{ Systemic ceftiofur treatments of cows } & $0:$ No & Referent & - & - & - & - & \multirow[t]{3}{*}{0.01} \\
\hline & & 1: Yes & 0.65 & 0.24 & 1.92 & $1.19 ; 3.10$ & 0.01 & \\
\hline & & 2: Unknown & 1.26 & 0.90 & 3.54 & $0.61 ; 20.5$ & 0.158 & \\
\hline \multirow[t]{10}{*}{ Streptomycin } & Intercept & & -0.36 & 0.33 & - & - & - & \\
\hline & Age of calf at sampling & Days & -0.06 & 0.01 & 0.95 & $0.92 ; 0.97$ & $<0.001$ & \multirow{3}{*}{0.05} \\
\hline & \multirow{2}{*}{ Feeding $\mathrm{WM}^{2}$ to calves } & 0 : Never & Referent & - & - & - & - & \\
\hline & & 1: Always to occasionally & 0.49 & 0.25 & 1.62 & $1.00 ; 2.65$ & 0.05 & \\
\hline & \multirow[t]{3}{*}{ Herd size } & 0: 28 to 62 cows & Referent & - & - & - & 0.025 & \multirow[t]{3}{*}{0.04} \\
\hline & & 1: 63 to 98 cows & 0.51 & 0.22 & 1.67 & $1.09 ; 2.56$ & 0.02 & \\
\hline & & 2: 100 to 1,175 cows & 0.42 & 0.21 & 1.57 & $1.02 ; 2.27$ & 0.04 & \\
\hline & \multirow{3}{*}{ Oral $\mathrm{DHS}^{3}$ for calves } & $0:$ No & Referent & - & - & - & - & \multirow[t]{3}{*}{0.001} \\
\hline & & 1: Yes & 0.55 & 0.22 & 1.73 & $1.14 ; 2.64$ & 0.01 & \\
\hline & & 2: Unknown & 1.16 & 0.30 & 3.19 & $1.76 ; 5.78$ & $<0.001$ & \\
\hline \multirow[t]{17}{*}{ Tetracycline } & Intercept & & -2.01 & 0.48 & & & & \\
\hline & Age of calf at sampling & Days & -0.06 & 0.02 & 0.94 & $0.91 ; 0.97$ & $<0.001$ & \multirow{5}{*}{0.03} \\
\hline & \multirow{4}{*}{ Calf housing } & 0 : Group pens with calves above $30 \mathrm{~d}$ & Referent & - & - & - & - & \\
\hline & & 1: Single pens & 0.70 & 0.31 & 2.01 & $1.10 ; 3.65$ & 0.02 & \\
\hline & & 2: Group pens with calves below $30 \mathrm{~d}$ & 0.77 & 0.35 & 2.17 & 1.09: 4.31 & 0.03 & \\
\hline & & 3: Other & 1.40 & 0.54 & 4.06 & $1.42 ; 11.64$ & 0.01 & \\
\hline & \multirow[t]{3}{*}{ Herd size } & 0: 28 to 62 cows & Referent & - & - & - & 0.025 & \multirow[t]{3}{*}{0.03} \\
\hline & & 1: 63 to 98 cows & 0.77 & 0.29 & 2.15 & $1.23 ; 3.77$ & 0.01 & \\
\hline & & 2: 100 to 1,175 cows & 0.57 & 0.30 & 1.76 & $0.99 ; 3.15$ & 0.05 & \\
\hline & \multirow[t]{4}{*}{ Predominant milking system } & 0: Tiestall milking & Referent & - & - & - & - & \multirow[t]{5}{*}{$<0.001$} \\
\hline & & 1: Milking parlor & 0.68 & 0.33 & 1.97 & $1.03 ; 3.74$ & 0.04 & \\
\hline & & 2: AMS & 0.20 & 0.31 & 1.22 & $0.67 ; 2.24$ & 0.51 & \\
\hline & & 3: Other & 1.64 & 0.42 & 5.14 & $2.27 ; 11.63$ & $<0.001$ & \\
\hline & Systemic tetracycline treatments of cows & Cases per 100 cow years & 0.07 & 0.02 & 1.07 & $1.03 ; 1.11$ & 0.001 & \\
\hline & \multirow[t]{3}{*}{ Systemic tetracycline treatments of calves } & $0:$ No & Referent & - & - & - & - & \multirow[t]{3}{*}{0.04} \\
\hline & & 1: Yes & 0.58 & 0.24 & 1.79 & $1.12 ; 2.84$ & 0.001 & \\
\hline & & 2: Unknown & -0.35 & 0.94 & 0.71 & $0.11: 4.31$ & 0.71 & \\
\hline \multirow[t]{5}{*}{ Kanamycin } & Intercept & & -2.78 & 0.31 & & & & \multirow{5}{*}{0.04} \\
\hline & Age of calf at sampling & 0: 7 to $11 \mathrm{~d}$ & Referent & - & - & - & - & \\
\hline & & 1: 12 to $19 \mathrm{~d}$ & 0.09 & 0.38 & 0.91 & $0.44 ; 1.91$ & 0.81 & \\
\hline & & 2: 20 to $28 \mathrm{~d}$ & -1.18 & 0.48 & 0.31 & $0.12 ; 0.79$ & 0.02 & \\
\hline & Herd size & Number of cows & 0.002 & 0.0005 & 1.00 & $1.00 ; 1.00$ & $<0.001$ & \\
\hline
\end{tabular}

을 $\quad{ }^{1}$ Robust standard errors (adjusted for clustering within herds).

$œ{ }^{2}$ Milk produced by a cow that was treated with antimicrobials during lactation was here denoted as waste milk.

Z ${ }^{3}$ Dihydrostreptomycin. 


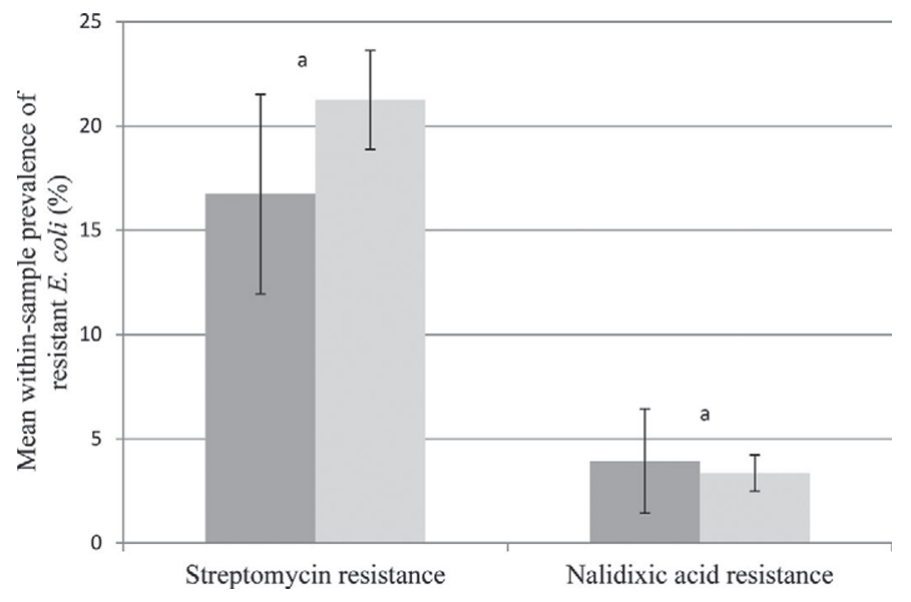

Figure 1. The mean within-sample prevalence and 95\% CI (-) of streptomycin- and nalidixic acid-resistant Escherichia coli from feces of calves raised on farms that never fed colostrum from cows given antimicrobial treatments at drying off (dark gray bars) or farms that fed such colostrum at least occasionally (light gray bars). Different letters indicate a significant difference $(P<0.05)$ in the mean within-sample prevalence for streptomycin-resistant or nalidixic acid-resistant $E$. coli isolates, respectively (results from univariable analysis).

though the association to $\mathrm{Ci}^{\mathrm{r}} E$. coli was borderline $(P$ $=0.06$; results not shown).

Use of Antimicrobials in Cows and Preweaned Calves. All farmers that submitted samples completed questionnaire 2. The annual TI for each antimicrobial is given in Table 3. A higher within-sample prevalence of $\mathrm{Sm}^{\mathrm{r}}$ and $\mathrm{Nal}^{\mathrm{r}}$ E. coli was observed among calves from farms that treated calves with oral preparations containing dihydrostreptomycin (DHS) than calves from farms that did not (Tables 4 and 5). Oral treatment with DHS also increased the likelihood of $\mathrm{Nal}^{\mathrm{r}}, \mathrm{Ci}^{\mathrm{r}}$, or $\mathrm{Sm}^{\mathrm{r}}$ in randomly selected isolates of E. coli (Tables 7 and 8).

Calves from farms using short-acting intramammary antimicrobials at drying off were more likely to shed $\mathrm{Sm}^{\mathrm{r}}$ E. coli than farms that did not use them, but the within-sample prevalence was unaffected (Table 4). The probability of isolating $\mathrm{Sm}^{\mathrm{r}} E$. coli also increased with an increasing proportion of cows per farm that were treated with long-acting dry cow antimicrobials (Table 4).

Farms that treated calves with systemic trimethoprimsulfonamide had a higher within-sample prevalence of $\mathrm{Nal}^{\mathrm{r}}$ E. coli compared with farms that did not (Table $5)$. Systemic treatment of cows with ceftiofur almost doubled the odds of isolating $\mathrm{Am}^{\mathrm{r}}$ E. coli (Table 7), and treatment of calves with the same drug increased the odds of finding $\mathrm{Ctx}^{\mathrm{r}}$ E. coli by a factor of 2.5 (Table 6). Additionally, the likelihood of finding $\mathrm{Tc}^{\mathrm{r}}, \mathrm{Nal}^{\mathrm{r}}$, and $\mathrm{Ci}^{\mathrm{r}}$ in a random $E$. coli increased with increasing TI of systemic tetracycline for cows (Tables 7 and 8). Systemic tetracycline for treatment of calves increased the odds of isolating $\mathrm{Tc}^{\mathrm{r}}$ or $\mathrm{Cm}^{\mathrm{r}}$ E. coli (Tables 7 and 8).

Farm Characteristics. The within-sample prevalence of $\mathrm{Nal}^{\mathrm{r}}$ and $\mathrm{Sm}^{\mathrm{r}}$ E. coli was significantly higher on farms with more than 62 cows than on farms with fewer than 62 cows. Calves on large farms were also more likely to have $\mathrm{Ctx}^{\mathrm{r}}$ (Table 6), $\mathrm{Sm}^{\mathrm{r}}$, and $\mathrm{Tc}^{\mathrm{r}}$ (Table 7 ) in a random E. coli. The odds of $\mathrm{Km}^{\mathrm{r}}, \mathrm{Nal}^{\mathrm{r}}$, and $\mathrm{Ci}^{\mathrm{r}}$ in a random E. coli also increased with herd size (Tables 7 and 8). A significant interaction was found between predominant herd breed and geographic location, meaning that calves on farms located in North or East Sweden and with predominantly Swedish Red or mixed-breed cows had a lower probability of $\mathrm{Nal}^{\mathrm{r}} E$. coli compared with calves on farms in South Sweden with predominantly Swedish Holstein cows (Table 5). However, a significantly higher prevalence of $\mathrm{Cm}^{\mathrm{r}} E$. coli was found in calves on farms in South Sweden. It was also more likely to find $\mathrm{Nal}^{\mathrm{r}}$ or $\mathrm{Ci}^{\mathrm{r}}$ in a random E. coli from Swedish Holstein herds than Swedish Red or mixed-breed herds (Table 8). However, calves from Swedish Holstein herds were less likely to shed $\mathrm{Cm}^{\mathrm{r}} E$. coli (Table 8). Use of a milking parlor or other milking facilities, was associated with increased odds of $\mathrm{Am}^{\mathrm{r}}$ and $\mathrm{Tc}^{\mathrm{r}}$ compared with AMS or tiestall milking (Table 7).

Calf Factors. Increasing age of the calf (days) was associated with a decline in the within-sample prevalence of $\mathrm{Sm}^{\mathrm{r}}$ (Table 4) and $\mathrm{Nal}^{\mathrm{r}}$ (Table 5) E. coli, and a decreasing probability of isolating $E$. coli resistant to all tested antimicrobials except cefotaxime (Tables 7 and 8). Cefotaxime-resistant E. coli were more common in calves housed in groups rather than in single pens (Table 6). Tetracycline-resistant E. coli were found more often in calves housed in groups together with young calves or in single pens than in group pen where at least one calf was $>30 \mathrm{~d}$ (Table 7 ). Calves were less likely to shed a high proportion of $\mathrm{Sm}^{\mathrm{r}} E$. coli between October and December than during the rest of the year (Tables 4).

\section{DISCUSSION}

The main objective of this study was to investigate the effect of feeding colostrum or milk from cows treated with antimicrobials on the shedding of resistant $E$. coli in feces from preweaned calves. Such milk or colostrum often contains antimicrobial residues (Pereira et al., 2014; Randall et al., 2014) and feeding it to calves would therefore favor resistant strains in the gastrointestinal tracts of calves. However, feeding WC or WT was not associated with an increase in the shedding of resistant $E$. coli. The lack of a significant association may be due to insufficient power but could also indicate 
Table 8. Risk factors for resistance to nalidixic acid, ciprofloxacin, sulfametoxasole or chloramphenicol among a random isolate of Escherichia coli in feces from preweaned dairy calves $(\mathrm{n}=720-729)$, according to multivariable logistic regression models

\begin{tabular}{|c|c|c|c|c|c|c|c|c|}
\hline $\begin{array}{l}\text { Resistance } \\
\text { phenotype }\end{array}$ & Variable & Level or unit & Coefficient & $\begin{array}{l}\text { Robust } \\
\operatorname{SE}^{1}(\beta)\end{array}$ & $\begin{array}{l}\text { Odds } \\
\text { ratios }\end{array}$ & $\begin{array}{c}95 \% \\
\text { CI }\end{array}$ & $\begin{array}{c}\text { Level } \\
P \text {-value }\end{array}$ & $\begin{array}{l}\text { Overall } \\
P \text {-value }\end{array}$ \\
\hline \multirow[t]{11}{*}{ Nalidixic acid } & Intercept & & -2.53 & 0.75 & & & & \\
\hline & Age of calf at sampling & Days & -0.08 & 0.02 & 0.92 & $0.88 ; 0.96$ & - & 0.001 \\
\hline & Herd size & Number of cows & 0.001 & 0.0007 & 1.00 & $1.00 ; 1.00$ & - & \\
\hline & \multirow[t]{2}{*}{ Feeding $\mathrm{WM}^{2}$ to calves lactation to calves } & 0 : Never & Referent & - & - & - & - & 0.04 \\
\hline & & 1: Always to occasionally & 1.47 & 0.72 & 4.34 & $0.06 ; 0.94$ & 0.04 & \\
\hline & \multirow[t]{2}{*}{ Oral $\mathrm{DHS}^{3}$ for calves } & $0:$ No & Referent & - & - & - & - & 0.04 \\
\hline & & 1: Yes & 0.81 & 0.35 & 2.26 & $1.13 ; 4.48$ & 0.02 & \\
\hline & \multirow[t]{3}{*}{ Predominant breed } & 0: Swedish Holstein & Referent & - & - & - & - & 0.02 \\
\hline & & 1: Swedish Red & -0.93 & 0.54 & 0.39 & $0.13 ; 1.12$ & 0.08 & \\
\hline & & 2: Mixed breeds & -0.82 & 0.31 & 0.44 & $0.24 ; 0.82$ & 0.009 & \\
\hline & Systemic tetracycline treatments of cows & Cases per 100 cow years & 0.07 & 0.03 & 1.07 & $1.02 ; 1.13$ & - & 0.01 \\
\hline \multirow[t]{9}{*}{ Ciprofloxacin } & Intercept & & -1.20 & 0.43 & & & & \\
\hline & Age of calf at sampling & Days & -0.07 & 0.02 & 0.93 & $0.89 ; 0.98$ & - & 0.002 \\
\hline & Herd size & Number of cows & 0.002 & 0.0007 & 1.00 & $1.00 ; 1.00$ & - & 0.01 \\
\hline & \multirow[t]{2}{*}{ Oral DHS for calves } & $0:$ No & Referent & - & - & - & - & 0.03 \\
\hline & & 1: Yes & 0.73 & 0.32 & 2.07 & $1.10 ; 3.91$ & & \\
\hline & \multirow[t]{3}{*}{ Predominant breed } & 0: Swedish Holstein & Referent & - & - & - & - & 0.007 \\
\hline & & 1: Swedish Red & -1.08 & 0.50 & 0.34 & $0.13 ; 0.91$ & 0.03 & \\
\hline & & 2: Mixed breeds & -0.89 & 0.31 & 0.41 & $0.23 ; 0.75$ & 0.004 & \\
\hline & Systemic tetracycline treatments of cows & Cases per 100 cow-years & 0.07 & 0.03 & 1.07 & $1.02 ; 1.13$ & - & 0.007 \\
\hline \multirow[t]{2}{*}{ Sulfametoxazole } & Intercept & & 0.02 & 0.25 & & & & \\
\hline & Age of calf at sampling & Days & -0.64 & 0.01 & 0.94 & $0.91 ; 0.96$ & $<0.001$ & \\
\hline \multirow[t]{9}{*}{ Chloramphenicol } & Intercept & & -1.46 & 0.72 & & & & \\
\hline & Age of calf at sampling & Days & -0.06 & 0.03 & 0.94 & $0.89 ; 0.99$ & 0.05 & 0.05 \\
\hline & \multirow[t]{2}{*}{ Located in South Sweden } & 0: No & Referent & - & - & - & - & 0.03 \\
\hline & & 1: Yes & -1.32 & 0.61 & 0.27 & $0.08 ; 0.88$ & 0.03 & \\
\hline & \multirow[t]{3}{*}{ Predominant breed } & 0: Swedish Red & Referent & - & - & - & & \multirow[t]{3}{*}{0.03} \\
\hline & & 1: Swedish Holstein & -2.69 & 1.09 & 0.07 & $0.01 ; 0.58$ & 0.01 & \\
\hline & & 2: Mixed breeds & -1.18 & 0.59 & 0.31 & $0.10 ; 0.98$ & 0.05 & \\
\hline & \multirow[t]{2}{*}{ Systemic tetracycline treatments of calves } & $0:$ No & Referent & - & - & - & - & \multirow[t]{2}{*}{0.01} \\
\hline & & 1: Yes & 1.39 & 0.56 & 4.02 & $1.34 ; 12.11$ & 0.01 & \\
\hline
\end{tabular}

${ }^{1}$ Robust standard errors (adjusted for clustering within herds).

$\stackrel{ก}{\frac{\Omega}{\Phi}} \quad{ }^{2}$ Milk produced by a cow that was treated with antimicrobials during lactation was here denoted as waste milk.

है Dihydrostreptomycin. 


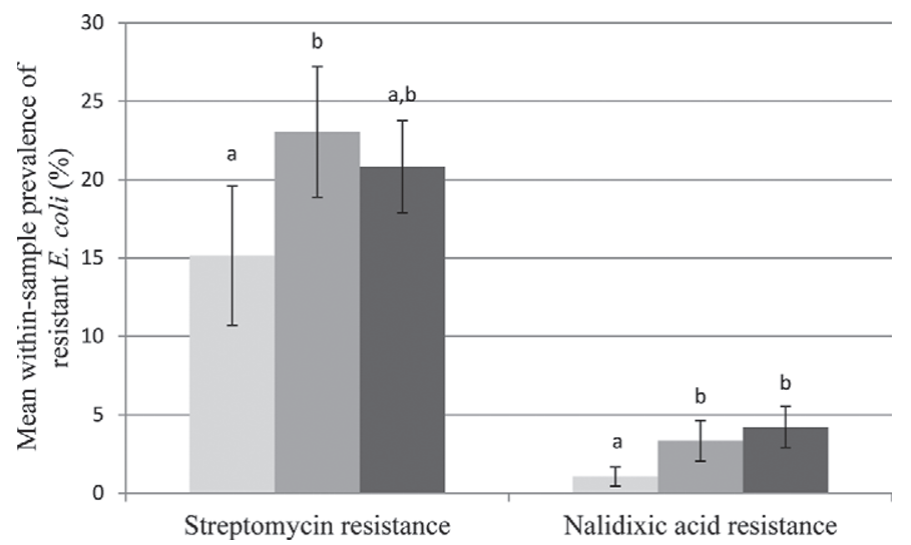

Figure 2. The mean within-sample prevalence and 95\% CI $(-)$ of streptomycin- and nalidixic acid-resistant Escherichia coli from feces of calves raised on farms that never fed calves milk from cows given lactation antimicrobial treatments (light gray bars), fed such milk during the withdrawal period only (medium gray bars), or during both the treatment and the withdrawal period (dark gray bars). Different letters indicate a significant difference $(P<0.05)$ in the mean withinsample prevalence for streptomycin-resistant or nalidixic acid-resistant E. coli isolates, respectively (results from univariable analysis).

that, by the time of parturition, the antimicrobials in colostrum either were eliminated or were present in such low concentrations that the susceptibility of $E$. coli in the gastrointestinal tract of preweaned calves was unaffected. Therefore, ingestion of WC or WT was probably not important for the shedding of resistant $E$. coli. To our knowledge, this is the first study to investigate the effect of feeding WC and WT on the shedding of resistant E. coli in feces of preweaned calves.

Calves from farms that fed WM to calves were more likely to shed $\mathrm{Sm}^{\mathrm{r}}$ or $\mathrm{Nal}^{\mathrm{r}}$ E. coli than calves on farms that discarded such milk, which is in agreement with previous studies (Wray et al., 1990; Aust et al., 2013; $\mathrm{Xu}$ et al., 2013). In Sweden, the bulk of WM is from cows treated with benzylpenicillin (Växa Sverige, 2012). Bearing in mind that E. coli is intrinsically resistant to benzylpenicillin and that this drug is, to some extent, hydrolyzed in the abomasum of the calves (Giguère et al., 2013), we hypothesized that milk containing benzylpenicillin residues would have a negligible effect on the susceptibility of fecal $E$. coli. It is therefore unlikely that the increased shedding of $\mathrm{Nal}^{\mathrm{r}}$ or $\mathrm{Sm}^{\mathrm{r}}$ E. coli observed in this study was directly caused by a selective pressure exerted by benzylpenicillin residues in milk. It could be the result of compositional changes in the gastrointestinal flora caused by this drug (Bridges et al., 1953; Dubos et al., 1963), but is more likely due to selective pressure from WM from cows treated with broad-spectrum antimicrobials (e.g., fluoroquinolones). It can be assumed that farms that fed WM from cows treated with benzylpenicillin also fed WM from cows treated with broad-spectrum antimicrobials, but in- formation on specific strategies for the latter was not sought in this study. Nonetheless, the significant interaction between fluoroquinolone use in cows and feeding WM to calves indicates that the shedding of $E$. coli with certain resistance traits would be more abundant after feeding WM from cows treated with the same or a related antimicrobial.

On the other hand, the probability of finding $E$. coli resistant to other tested antimicrobials was not significantly affected by feeding WM to calves. Wray et al. (1990) and Aust et al. (2013) also observed that such feeding practices affected only some resistance traits and not others. This phenomenon may be because different mechanisms account for the selection of resistant traits or that different methods exist for susceptibility testing. By using selective media for $\mathrm{Sm}^{\mathrm{r}}$, Nal${ }^{\mathrm{r}}$, and $\mathrm{Ctx}^{\mathrm{r}}$, the susceptibility of multiple isolates was tested simultaneously (Scott et al., 2011). This method was therefore more sensitive to subtle differences in the prevalence of resistance than methods based on susceptibility testing of only a single or few isolates. If selective media had been used for all tested antimicrobials in this study, feeding WM might have been significantly associated with other resistance traits.

We can assume that WM produced during ongoing treatment contains higher concentrations of antimicrobial residues than WM from the withdrawal period. Ingestion of VM from the treatment period would therefore be more likely to cause an increase in the prevalence of resistant $E$. coli. However, we found no significant difference in the shedding of $\mathrm{Nal}^{\mathrm{r}}$ or $\mathrm{Sm}^{\mathrm{r}} E$. coli in calves on farms that fed WM during treatment compared with farms where VM was fed only during the withdrawal period. This indicates that low concentrations of antimicrobials are sufficient to exert a selective pressure on the gastrointestinal flora, as reported elsewhere (Gullberg et al., 2011).

The effect of feeding WM seems to be relatively subtle and was clearly not the main cause of shedding resistant E. coli. However, shedding of resistant E. coli persists longer among WM-fed calves (Brunton et al., 2014). Hence, this feeding practice is probably important in the maintenance of resistant bacteria in the intestinal flora. It is therefore recommended to minimize the feeding of VM to reduce the prevalence of resistant $E$. coli in the gut of calves.

The purpose was also to investigate whether antimicrobial use in preweaned dairy calves and cows was associated per se with increased shedding of resistant E. coli. Our results showed that therapy with some antimicrobials for both cows and calves was positively associated with the presence of some resistance phenotypes. Oral administration of DHS to calves increased the shedding of $\mathrm{Sm}^{\mathrm{r}}, \mathrm{Nal}^{\mathrm{r}}$, and $\mathrm{Ci}^{\mathrm{r}}$ E. coli. Previous 
studies have shown that oral DHS may select for E. coli resistant to multiple types of antimicrobials, probably because of limited absorption from the gastrointestinal tract (Gaines et al., 1978).

The use of both long- and short-acting intramammary dry cow antimicrobials increased the shedding of $\mathrm{Sm}^{\mathrm{r}}$ $E$. coli in the calves. This result is likely because most of the products licensed for dry cow therapy in Sweden contain an aminoglycoside, often DHS (Växa Sverige, 2012). Likewise, Mollenkopf et al. (2010) observed that intramammary-administered dry cow antimicrobials influence the shedding of resistant $E$. coli from the treated cow. The environments of dairy farms probably favor the sharing of bacteria among animals; meaning that resistant bacteria shed by cows may propagate to other age categories on the farm, including calves. Aminoglycosides such as DHS are assumed to have a synergistic effect with benzylpenicillin, and a combination of the 2 would therefore be beneficial in the treatment of infections caused by bacteria with moderate susceptibility to both antimicrobials (Giguère et al., 2013). The synergistic effect may be of limited value, however, because many gram-negative bacteria causing intramammary infections have only moderate susceptibility to benzylpenicillin. Furthermore, $\beta$-lactamaseproducing staphylococci are fully resistant to benzylpenicillin (Giguère et al., 2013). The value of adding aminoglycosides to intramammary tubes can therefore be questioned, and such combination preparations may not be justified due to their potential selection for resistant E. coli, as observed in this study. Unfortunately, long-acting antimicrobials without an aminoglycoside component are not yet available in Sweden (Medical Products Agency, 2014).

Systemically administered tetracycline was associated with higher odds for $\mathrm{Tc}^{\mathrm{r}}, \mathrm{Cm}^{\mathrm{r}}$, and $\mathrm{Nal}^{\mathrm{r}}$ in a random E. coli. Most of the $\mathrm{Cm}^{\mathrm{r}}$ and $\mathrm{Nal}^{\mathrm{r}}$ E. coli isolates were also resistant to tetracycline (results not shown), and the link between use and resistance is therefore probably due to co-selection of resistance determinants. Likewise, almost two-thirds of the randomly selected $E$. coli isolates from calves having at least one $\mathrm{Nal}^{\mathrm{r}} E$. coli isolate were resistant to sulfametoxazole (results not shown), which may also be indicative of co-selection. Treatment with ceftiofur, a third-generation cephalosporin, was rare in this study and is rare in Sweden in general (Växa Sverige, 2012). Despite this, treating cows and calves with ceftiofur had a significant effect on the prevalence of $\mathrm{Am}^{\mathrm{r}}$ or $\mathrm{Ctx}^{\mathrm{r}}$ E. coli, respectively. Third-generation cephalosporins are considered by the World Health Organization to be critically important drugs in human medicine (World Health Organization, 2012) and use of these drugs should therefore be restricted. The results of the current study indicate that measures to reduce the prevalence of resistance among bacteria from calves should include prudent use of antimicrobials for all cattle on the farm, not only for calves.

Besides calf feeding with VM and use of antimicrobials, other risk factors were identified for the presence of resistant E. coli isolates. As observed in previous studies (Hoyle et al., 2004; Edrington et al., 2012; Watson et al., 2012), resistance in E. coli declined with increasing age of the calf. The housing of the calf was also important for some resistance phenotypes, a link reported earlier by Short et al. (2012). It is likely that group housing enhances the spread of resistant E. coli. Nevertheless, when some of the calves in the pen were older than 1 mo, the prevalence of resistant E. coli among calves was lower in the group pens than in the single pens. This may be due to a dilution effect, with shedding of more susceptible $E$. coli by older calves. Fewer calves carried $\mathrm{Sm}^{\mathrm{r}}$ E. coli and in lower numbers during October to December compared with the rest of year. A similar seasonal variation was observed in a longitudinal study for the isolation of ESBL-producing E. coli from adult dairy cattle, where significantly fewer ESBL-producing E. coli were found during November than the rest of the year (Watson et al., 2012). Whether this difference is due to seasonal variations in temperature, humidity, or other factors or occurs solely by chance remains to be determined.

As observed by de Verdier et al. (2012), large herd size was a significant predictor for the presence of resistance to multiple types of antimicrobials. Large herds are more likely than small ones to have disease problems (Gulliksen et al., 2009; Hill et al., 2009), and hence have more frequent use of antimicrobial drugs. We assume that transmission pathways are more abundant and that there is increased movement of people and animals between and within large farms compared with small farms. Finally, calves from farms where cows were milked in a milking parlor or other milking facilities (e.g., a milking carousel) had more $\mathrm{Tc}^{\mathrm{r}}$ and $\mathrm{Am}^{\mathrm{r}}$ E. coli than calves from farms with tiestall milking or AMS. Here, the milking system is probably a surrogate for other important risk factors not elucidated in this study.

The epidemiology of antimicrobial resistance in calves is clearly multifactorial. Although some factors in this study were shown to increase the prevalence of resistant bacteria, it is likely that these factors only help to maintain resistant strains that have already colonized the gastrointestinal tract. Future studies should therefore focus on finding the source for resistant $E$. coli and to further address which host-specific and environmental factors are responsible for the colonization and persistence of these strains in the gastrointestinal tract of young calves. 
The secondary objective of the study was to describe the prevalence of antimicrobial-resistant $E$. coli in feces from preweaned dairy calves in Sweden. Streptomycinresistant $E$. coli seemed to be widespread, whereas the occurrence of $\mathrm{Nal}^{\mathrm{r}}$ and $\mathrm{Ctx}^{\mathrm{r}}$ E. coli was more farm-specific. Plasmid-mediated genes conferring streptomycinresistance (strA and $\operatorname{str} B$ ) are widely distributed in the environment, and the high prevalence of $\mathrm{Sm}^{\mathrm{r}} E$. coli may therefore be explained by frequent gene transfer events between bacteria of different origin (Sundin and Bender, 1996). On the other hand, the shedding of $\mathrm{Nal}^{\mathrm{r}}$ and $\mathrm{Ctx}^{\mathrm{r}}$ E. coli is more likely due to certain farm characteristics or routines. In addition, $\mathrm{Nal}^{\mathrm{r}} E$. coli were more commonly shed by calves on farms in South Sweden, which could be explained by transmission of resistant clones within certain areas of Sweden. Likewise, clonal spread of fluoroquinolones-resistant $E$. coli has been observed in calves in Italy (Marchese et al., 2012).

Genes encoding ESBL and pAmpC were detected in $E$. coli from calves in this study, which was the first time such genes were confirmed for $E$. coli obtained from Swedish cattle. In 2009, none of the 256 fattened calves (6-8 mo old) screened at slaughter in Sweden carried these genes (SVARM, 2009). It is uncertain whether this is due to the difference in age of the calves sampled or whether this finding reflects an emergence of ESBL-producing E. coli in cattle in Sweden and globally (Livermore and Woodford, 2006).

One potential risk with the present study design is that conclusions were drawn based on the susceptibility testing of samples obtained from no more than 3 calves per farm. By sampling only a fraction of the whole population, there is always a risk that it is not representative of the whole population. However, this design has been used previously to assess the importance of different risk factors for the presence of resistant $E$. coli in feces of calves (Di Labio et al., 2007; de Verdier et al., 2012). In addition, collecting samples from more than 3 calves would have significantly decreased the willingness of farmers to participate in the study.

\section{CONCLUSIONS}

Antimicrobial-resistant E. coli isolates were commonly isolated from feces of preweaned dairy calves in Sweden. Feeding WM, but not WC or WT, significantly increased the likelihood of shedding resistant E. coli by preweaned calves. The use of certain antimicrobials for calves and cows, as well as some farm and calf characteristics, were also associated with increased shedding of $E$. coli with specific resistance traits. The presence of resistance in E. coli isolates from calves is clearly due to multiple factors, but minimizing the feeding of milk from cows treated with antimicrobials during lactation should lower the prevalence of resistant $E$. coli in feces from calves.

\section{ACKNOWLEDGMENTS}

The Swedish Farmers' Foundation for Agricultural Research (Stockholm, Sweden) is acknowledged for financing the study. Participating farmers are acknowledged for contributing samples and questionnaire data. Växa Sverige (Stockholm, Sweden) is acknowledged for providing data from national databases, as well as Stefan Börjesson (National Veterinary Institute, Uppsala, Sweden) for conducting the sequencing of ESBL genes.

\section{REFERENCES}

Aust, V., K. Knappstein, H. J. Kunz, H. Kaspar, J. Wallmann, and M. Kaske. 2013. Feeding untreated and pasteurized waste milk and bulk milk to calves: Effects on calf performance, health status and antibiotic resistance of faecal bacteria. J. Anim. Physiol. Anim. Nutr. (Berl.) 97:1091-1103. http://dx.doi.org/10.1111/jpn.12019.

Berge, A. C., E. R. Atwill, and W. M. Sischo. 2005. Animal and farm influences on the dynamics of antibiotic resistance in faecal Escherichia coli in young dairy calves. Prev. Vet. Med. 69:25-38. http://dx.doi.org/10.1016/j.prevetmed.2005.01.013.

Berge, A. C. B., D. A. Moore, and W. M. Sischo. 2006. Field trial evaluating the influence of prophylactic and therapeutic antimicrobial administration on antimicrobial resistance of fecal Escherichia coli in dairy calves. Appl. Environ. Microbiol. 72:3872-3878. http:// dx.doi.org/10.1128/AEM.02239-05.

Bridges, J. H., I. A. Dyer, and J. J. Powers. 1953. Penicillin and streptomycin affect the microflora of the intestinal tract of pigs. J. Anim. Sci. 12:96-101.

Brunton, L. A., D. Duncan, N. G. Coldham, L. C. Snow, and J. R. Jones. 2012. A survey of antimicrobial usage on dairy farms and waste milk feeding practices in England and Wales. Vet. Rec. 171:296-302. http://dx.doi.org/10.1136/vr.100924.

Brunton, L. A., H. E. Reeves, L. C. Snow, and J. R. Jones. 2014. A longitudinal field trial assesing the impact of feeding waste milk containing antibiotic residues on the prevalence of ESBL-producing Escherichia coli in calves. Prev. Vet. Med. 117:403-412. http:// dx.doi.org/10.1016/j.prevetmed.2014.08.005.

Call, D. R., M. A. Davis, and A. A. Sawant. 2008. Antimicrobial resistance in beef and dairy cattle production. Anim. Health Res. Rev. 9:159-167. http://dx.doi.org/10.1017/S1466252308001515.

CLSI. 2013. Performance Standards for Antimicrobial Disk and Dilution Susceptibility Tests for Bacteria Isolated from Animals; Approved Standard (VET01-A4). 4th ed. Clinical and Laboratory Standards Institute (CLSI), Wayne, PA.

de Verdier, K., A. Nyman, C. Greko, and B. Bengtsson. 2012. Antimicrobial resistance and virulence factors in Escherichia coli from Swedish dairy calves. Acta Vet. Scand. 54:2. http://dx.doi. org/10.1186/1751-0147-54-2.

DeFrancesco, K. A., R. N. Cobbold, D. H. Rice, T. E. Besser, and D. D. Hancock. 2004. Antimicrobial resistance of commensal Escherichia coli from dairy cattle associated with recent multi-resistant salmonellosis outbreaks. Vet. Microbiol. 98:55-61. http://dx.doi. org/10.1016/j.vetmic.2003.10.017.

Di Labio, E., G. Regula, A. Steiner, R. Miserez, A. Thomann, and U. Ledergerber. 2007. Antimicrobial resistance in bacteria from Swiss veal calves at slaughter. Zoonoses Public Health 54:344-352. http://dx.doi.org/10.1111/j.1863-2378.2007.01071.x.

Dohoo, I., W. Martin, and H. Stryhn. 2010. Veterinary Epidemiologic Research. 2nd ed. VER Inc., Charlottetown, Prince Edward Island, Canada. 
Donaldson, S. C., B. A. Straley, N. V. Hegde, A. A. Sawant, C. DebRoy, and B. M. Jayarao. 2006. Molecular epidemiology of ceftiofur-resistant Escherichia coli isolates from dairy calves. Appl. Environ. Microbiol. 72:3940-3948. http://dx.doi.org/10.1128/ AEM.02770-05.

Dubos, R., R. W. Schaedler, and M. Stephens. 1963. The effect of antibacterial drugs on the fecal flora of mice. J. Exp. Med. 117:231243. http://dx.doi.org/10.1084/jem.117.2.231.

Duse, A., K. P. Waller, U. Emanuelson, H. E. Unnerstad, Y. Persson, and B. Bengtsson. 2013. Farming practices in Sweden related to feeding milk and colostrum from cows treated with antimicrobials to dairy calves. Acta Vet. Scand. 55:49. http://dx.doi. org/10.1186/1751-0147-55-49.

Edrington, T. S., R. L. Farrow, B. H. Carter, A. Islas, G. R. Hagevoort, T. R. Callaway, R. C. Andersson, and D. J. Nisbet. 2012. Age and diet effects on fecal populations and antibiotic resistance of a multi-drug resistant Escherichia coli in dairy calves. Agric. Food Anal. Bacteriol. 2:162-174.

European Food Safety Authority. 2011. EU summary report on antimicrobial resistance in zoonotic and indicator bacteria from humans, animals and food 2011. EFSA J. 11:3196 10.2903/j.efsa.2013.3196.

European Union. 2003. Regulation (EC) no 1059/2003 of the European parliament and of the council of 26 May 2003 on the establishment of a common classification of territorial units for statistics (NUTS). Off. J. L 154:1-41.

Gaines, S. A., L. D. Rollins, R. P. Silver, and M. Washington. 1978. Effect of low concentrations of dihydrostreptomycin on drug resistance in enteric bacteria. Antimicrob. Agents Chemother. 14:252-256.

Giguère, S., J. F. Prescott, and P. M. Dowling. 2013. Antimicrobial Therapy in Veterinary Medicine. 5th ed. Wiley Blackwell, Ames, IA. $10.1002 / 9781118675014$

Gullberg, E., S. Cao, O. G. Berg, C. Ilbäck, L. Sandegren, D. Hughes, and D. I. Andersson. 2011. Selection of resistant bacteria at very low antibiotic concentrations. PLoS Pathog. 7:e1002158 http:// dx.doi.org/10.1371/journal.ppat.1002158.

Gulliksen, S. M., E. Jor, K. I. Lie, I. S. Hamnes, T. Løken, J. Akerstedt, and O. Osterås. 2009. Enteropathogens and risk factors for diarrhea in Norwegian dairy calves. J. Dairy Sci. 92:5057-5066. http://dx.doi.org/10.3168/jds.2009-2080.

Hill, A. E., A. L. Green, B. A. Wagner, and D. A. Dargatz. 2009. Relationship between herd size and annual prevalence of and primary antimicrobial treatments for common diseases on dairy operations in the United States. Prev. Vet. Med. 88:264-277. http://dx.doi. org/10.1016/j.prevetmed.2008.12.001.

Houe, H., A. K. Ersbøll, and N. Toft. 2004. Introduction to Veterinary Epidemiology. 1st ed. Biofolia, Frederiksberg, Denmark.

Hoyle, D. V., D. J. Shaw, H. I. Knight, H. C. Davison, M. C. Pearce, J. C. Low, G. J. Gunn, and M. E. J. Woolhouse. 2004. Age-related decline in carriage of ampicillin-resistant Escherichia coli in young calves. Appl. Environ. Microbiol. 70:6927-6930. http://dx.doi. org/10.1128/AEM.70.11.6927-6930.2004.

Khachatryan, A. R., D. D. Hancock, T. E. Besser, and D. R. Call. 2004. Role of calf-adapted Escherichia coli in maintenance of antimicrobial drug resistance in dairy calves. Appl. Environ. Microbiol. 70:752-757. http://dx.doi.org/10.1128/AEM.70.2.752757.2004 .

Livermore, D. M., and N. Woodford. 2006. The beta-lactamase threat in Enterobacteriaceae, Pseudomonas and Acinetobacter. Trends Microbiol. 14:413-420. http://dx.doi.org/10.1016/j.tim.2006.07.008.

Marchese, A., E. Coppo, R. Barbieri, S. Zoppi, C. Pruzzo, F. Rossi, S. Bergagna, A. Dondo, and E. Debbia. 2012. Characterization of fluoroquinolone-resistant Escherichia coli causing septicemic colibacillosis in calves in Italy: Emergence of a multiresistant O78 clonal group. Microb. Drug Resist. 18:94-99. http://dx.doi. org/10.1089/mdr.2011.0053.

Medical Products Agency. 2014. Läkemedelsfakta-Utökad sökning. Accessed Aug 28, 2014. http://www.lakemedelsverket.se/LMF/.

Miller, J. M., and J. W. Wright. 1982. Spot indole test: Evaluation of four reagents. J. Clin. Microbiol. 15:589.
Mollenkopf, D. F., C. Glendening, T. E. Wittum, J. A. Funk, L. A. Tragesser, and P. S. Morley. 2010. Association of dry cow therapy with the antimicrobial susceptibility of fecal coliform bacteria in dairy cows. Prev. Vet. Med. 96:30-35. http://dx.doi. org/10.1016/j.prevetmed.2010.05.014.

Mörk, M., A. Lindberg, S. Alenius, I. Vågsholm, and A. Egenvall. 2009. Comparison between dairy cow disease incidence in data registered by farmers and in data from a disease-recording system based on veterinary reporting. Prev. Vet. Med. 88:298-307. http://dx.doi.org/10.1016/j.prevetmed.2008.12.005.

Mörk, M. J., C. Wolff, A. Lindberg, I. Vågsholm, and A. Egenvall. 2010. Validation of a national disease recording system for dairy cattle against veterinary practice records. Prev. Vet. Med. 93:183-192. http://dx.doi.org/10.1016/j.prevetmed.2009.09.016.

Pereira, R. V., J. D. Siler, R. C. Bicalho, and L. D. Warnick. 2014. Multiresidue screening of milk withheld for sale at dairy farms in central New York State. J. Dairy Sci. http://dx.doi.org/10.3168/ jds.2013-7421.97:1513-1519.

Pérez-Pérez, F. J., and N. D. Hanson. 2002. Detection of plasmidmediated AmpC beta-lactamase genes in clinical isolates by using multiplex PCR. J. Clin. Microbiol. 40:2153-2162. http://dx.doi. org/10.1128/JCM.40.6.2153-2162.2002.

Randall, L., K. Heinrich, R. Horton, L. Brunton, M. Sharman, V. Bailey-Horne, M. Sharma, I. McLaren, N. Coldham, C. Teale, and J. Jones. 2014. Detection of antibiotic residues and association of cefquinome residues with the occurrence of extended-spectrum $\beta$-lactamase (ESBL)-producing bacteria in waste milk samples from dairy farms in England and Wales in 2011. Res. Vet. Sci. 96:15-24. http://dx.doi.org/10.1016/j.rvsc.2013.10.009.

Sato, K., P. C. Bartlett, and M. A. Saeed. 2005. Antimicrobial susceptibility of Escherichia coli isolates from dairy farms using organic versus conventional production methods. J. Am. Vet. Med. Assoc. 226:589-594. http://dx.doi.org/10.2460/javma.2005.226.589.

Scott, H. M., B. Norby, and G. H. Loneragan. 2011. Antimicrobial resistance surveillance: Bacterial prevalence estimates are not enough. Epidemiol. Sante Anim. 59-60:182-184.

Short, D., R. Pereira, W. Sischo, L. Warnick, L. Jones, J. Silver, and M. A. Davis. 2012. Impact of dairy calf housing on antimicrobial resistance. Accessed May 28, 2014. http://extension.wsu.edu/vetextension/MART/Documents/DavisCalfHousing.pdf.

Sørum, H., and M. Sunde. 2001. Resistance to antibiotics in the normal flora of animals. Vet. Res. 32:227-241. http://dx.doi. org/10.1051/vetres:2001121.

Summers, A. O. 2002. Generally overlooked fundamentals of bacterial genetics and ecology. Clin. Infect. Dis. 34:S85-S92. http://dx.doi. org $/ 10.1086 / 340245$.

Sundin, G. W., and C. L. Bender. 1996. Dissemination of the $\operatorname{str} A-\operatorname{str} B$ streptomycin-resistance genes among commensal and pathogenic bacteria from humans, animals, and plants. Mol. Ecol. 5:133-143. http://dx.doi.org/10.1111/j.1365-294X.1996.tb00299.x.

Sundsfjord, A., G. S. Simonsen, B. C. Haldorsen, H. Haaheim, S.-O. Hjelmevoll, P. Littauer, and K. H. Dahl. 2004. Genetic methods for detection of antimicrobial resistance. APMIS 112:815-837. http://dx.doi.org/10.1111/j.1600-0463.2004.apm11211-1208.x.

SVARM. 2006. Swedish Veterinary Antimicrobial Resistance Monitoring (SVARM) 2006. National Veterinary Institute (SVA), Uppsala, Sweden.

SVARM. 2009. Swedish Veterinary Antimicrobial Resistance Monitoring (SVARM) 2009. National Veterinary Institute (SVA), Uppsala, Sweden.

van den Bogaard, A. E., and E. E. Stobberingh. 2000. Epidemiology of resistance to antibiotics: Links between animals and humans. Int. J. Antimicrob. Agents 14:327-335. http://dx.doi.org/10.1016/ S0924-8579(00)00145-X.

Växa Sverige. 2012. Animal Health 2011/2012: Annual report from the animal health section. Växa Sverige, Stockholm, Sweden.

Vieira, A. R., S. Wu, L. B. Jensen, A. Dalsgaard, H. Houe, H. C. Wegener, D. L. F. Wong, and H.-D. Emborg. 2008. Using data on resistance prevalence per sample in the surveillance of antimicrobial resistance. J. Antimicrob. Chemother. 62:535-538. 
Villarroel, A., P. S. Morley, T. E. Wittum, and D. S. Bolte. 2006. Use of a simulation model to evaluate sampling strategies for characterization of antimicrobial resistance in non-type-specific Escherichia coli isolated from dairy cows. Am. J. Vet. Res. 67:951-956. http://dx.doi.org/10.2460/ajvr.67.6.951.

Watson, E., S. Jeckel, L. Snow, R. Stubbs, C. Teale, H. Wearing, R. Horton, M. Toszeghy, O. Tearne, J. Ellis-Iversen, and N. Coldham. 2012. Epidemiology of extended spectrum beta-lactamase $E$. coli (CTX-M-15) on a commercial dairy farm. Vet. Microbiol. 154:339-346. http://dx.doi.org/10.1016/j.vetmic.2011.07.020.

Wernli, D., T. Haustein, J. Conly, Y. Carmeli, I. Kickbusch, and S. Harbarth. 2011. A call for action: the application of the international health regulations to the global threat of antimicrobial resistance. PLoS Med. 8:e1001022 http://dx.doi.org/10.1371/journal. pmed.1001022.

Woodford, N., E. J. Fagan, and M. J. Ellington. 2006. Multiplex PCR for rapid detection of genes encoding CTX-M extended-spectrum
B-lactamases. J. Antimicrob. Chemother. 57:154-155. http:// dx.doi.org/10.1093/jac/dki412.

World Health Organization. 2012. Critically Important Antimicrobials for Human Medicine. 3rd rev. World Health Organization (WHO), Geneva, Switzerland.

Wray, C., S. Furniss, and C. L. Benham. 1990. Feeding antibioticcontaminated waste milk to calves-effects on physical performance and antibiotic sensitivity of gut flora. Br. Vet. J. 146:80-87. http://dx.doi.org/10.1016/0007-1935(90)90080-M

Xu, F., U. Rösler, A. Riese, M. Baumann, J. Zhao, H. Wei, X. Liu, and K. Kreusukon. 2013. First findings on the prevalence of Extended-Spectrum $\beta$-Lactamases producing Escherichia coli (ESBLproducing E. coli) and risk factors in dairy farms in Beijing area, China. Pages 83-87 in Proc 10th Year Anniversary of Veterinary Public Health Centre for Asia Pacific, Chiang Mai, Thailand. 